\title{
PRENATAL DENTAL CARE: EVALUATION OF PROFESSIONAL KNOWLEDGE OF OBSTETRICIANS AND DENTISTS IN THE CITIES OF LONDRINA/PR AND BAURU/ SP, BRAZIL, 2004
}

\author{
Régia Luzia ZANATA ${ }^{1}$, Karen Barros Parron FERNANDES ${ }^{2}$, Patrícia Silva Lopes NAVARRO ${ }^{3}$
}

1- DDS, MSc, PhD, Bauru School of Dentistry, University of São Paulo, Bauru, SP, Brazil.

2- DDS, MSc, PhD, Professor of Pharmacology, Dental School, University of Northern Parana, Londrina, PR, Brazil.

3- DDS, Graduate student, Dental School, University of Northern Parana, Londrina, PR, Brazil.

Corresponding address: Dra. Régia Luzia Zanata - Faculdade de Odontologia de Bauru - Universidade de São Paulo - UBAS - Setor Odontológico - Al. Octávio Pinheiro Brisolla 9-75 - 17012-901, Bauru - SP, Brazil - Phone: +55 1432358004 - e-mail: regiaz@usp.br

Received: October 5, 2007 - Modification: November 9, 2007 - Accepted: January 14, 2008

\begin{abstract}
$T_{\text {he }}$

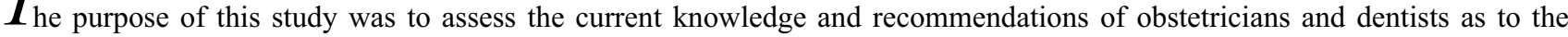
dental care to pregnant patients in the cities of Londrina/PR and Bauru/SP, Brazil. Questionnaires were distributed to professionals of both cities, arguing on the following issues: oral health during pregnancy; contact between prenatal care and dental care providers; prenatal fluoride supplementation; selection of therapeutic agents for local anesthesia, pain control and treatment of infection; and dental procedures that can be performed during each trimester. Data were analyzed by frequency of responses and statistical analyses were carried out using $\mathrm{X}^{2}$ (type of workplace/service) and t test (time since graduation), significant if $p<0.05$. Seventy-nine obstetricians and 37 dentists responded the questionnaires. Most physicians referred the patient to dental care only when a source of dental problem was mentioned, limiting the adoption of a preventive approach. Forty-three percent of dentists and 34\% of obstetricians did not know the potential contribution of periodontal infection as a risk factor for preterm low birth-weight babies. There was divergence from scientific literature as to the recommendation of local anesthetics (dentists and obstetricians), prenatal fluoride supplementation (obstetricians) and dental radiographs (dentists). The findings of this survey with dentists and obstetricians showed that dental management during pregnancy still presents some deviations from scientific literature recommendations, indicating the need to update these health care professionals in order to establish guidelines for prenatal dental care.
\end{abstract}

Key words: Prenatal care. Dental care. Primary health care. Dental health services.

\section{INTRODUCTION}

Several systems in the organism suffer changes during pregnancy. Gastrointestinal disorders are frequently observed, and there may be hepatic dysfunction, glycemic alterations, hyperventilation and dyspnea, tachycardia, blood pressure alterations, gestational diabetes, hemodilution and anemia ${ }^{8,23}$. In the oral cavity, due to increased levels of estrogen and progesterone, there is hypervascularization of the periodontium and changes in collagen production, increasing the vascular permeability and making the gingival tissue more susceptible to local irritants (bacterial biofilm). There may be exacerbated inflammatory alterations such as gingivitis, gingival hyperplasia and granuloma gravidarum or pregnancy tumor, and worsening of preexisting periodontitis ${ }^{2}$. Saliva composition is also altered, with reduction in calcium and phosphate content and reduction in saliva $\mathrm{pH}^{21}$.

Untreated dental problems are evident in pregnant women with low educational level and low income ${ }^{20,28,29}$. Given that basic measures including an educative approach, removal of dental biofilm and elimination of infection foci may contribute to improve the life quality of the pregnant woman and the baby ${ }^{10,12,29}$, dental care during prenatal assistance should be stimulated as a public health measure, aiming at an integrated action of medical, dental and nursing teams ${ }^{17}$.

The purpose of this questionnaire-based study was to assess the knowledge and practical measures of dentists and obstetricians regarding the prenatal dental care in two Brazilian cities (Londrina/PR and Bauru/SP), in order to verify whether dental management during pregnancy still 
presents deviations from scientific literature recommendation.

\section{MATERIALAND METHODS}

Two questionnaires, $\mathrm{A}$ and $\mathrm{B}$, were designed for application to obstetricians and dentists, respectively. Both questionnaires objectively addressed questions related to oral health (knowledge of oral alterations during pregnancy; influence of oral diseases during pregnancy); level of professional interaction (situations in which medical consultation is advised; referral of pregnant women to dental care); administration of prenatal fluoride; first-choice antibiotics, analgesics and anti-inflammatory drugs; utilization of local anesthetics; type of dental care recommended and period of accomplishment (emergency and elective care, exposure to radiation). Regarding drug administration, the questions addressed individually the antibiotics, analgesics, anti-inflammatory drugs and local anesthetics. The question on recommendation of local anesthetics addressed individually indication of the anesthetic salt and presence of vasoconstrictors. Orientation was provided as to the indication for pregnancy without complications. The questionnaires also argued about professional exercise, such as period and sector of work.

The research project was independently reviewed and approved by the Institutional Review Board of University of Northern Paraná. The questionnaires were sent to professionals in the cities of Bauru/SP and Londrina/PR, Brazil, between May and September 2004.

Based on data supplied by the Medical Association of Londrina, 101 questionnaires type A were mailed to obstetricians from Londrina and metropolitan region. Fiftyeight questionnaires were returned, representing $57.4 \%$ of professionals. In the city of Bauru, where dental care has been systematically included in the prenatal care provided by the municipal public health service since 2002 , the questionnaires were responded by obstetricians working in the municipal public health service, adding up to 21 obstetricians, which represents nearly $30 \%$ of the professionals in the city. Thirty-seven dentists from the municipal public health service of Bauru responded the questionnaire type B.

Data were descriptively collected and analyzed by frequency of responses. The groups were compared as to the type of workplace $\left(\mathrm{X}^{2}\right.$ test $)$ and time since graduation $(\mathrm{t}$ test). Differences were considered statistically significant at $\mathrm{p}<0.05$.

\section{RESULTS}

\section{Obstetricians}

A total of 79 professionals were interviewed, being 58 in the city of Londrina/PR and 21 in the city of Bauru/SP. Regarding the type of workplace, 28 obstetricians worked exclusively in private practice, 30 worked both in private practice and public health centers, 5 were professors, 9 worked in all three activities, and 7 worked exclusively in public health centers. The time since graduation ranged from 2 to 45 years (mean 19 years).

With regard to the question "Would you like to be consulted by your pregnant patients' dentist before dental care is performed? In which situations?", 22 obstetricians $(27.8 \%)$ responded that there was no need of previous consultation before any procedure. This response was significantly more frequent among professionals working in public health centers $(\mathrm{n}=46)$ compared to those working exclusively in private practice ( $\mathrm{p}=0.016 ; \mathrm{X}^{2}$ test). Fifty-seven professionals (72\%) would like to be consulted, depending on the type of the clinical intervention (Figure 1).

Concerning the viability of dental intervention according to the gestational period, most obstetricians (94\%) mentioned that intervention may be performed at any period, preferably between the 16th and 32nd weeks of pregnancy. Three professionals considered the intervention as adequate only during the second trimester and one professional contraindicated dental treatment during pregnancy.

Taking of dental radiographs with adequate protection (lead apron and collar) was considered safe throughout pregnancy by 68 professionals $(86 \%)$. It was contraindicated during the first trimester by 9 professionals $(11.4 \%)$ and contraindicated throughout pregnancy by 2 obstetricians (2.5\%).

Beta-lactam antibiotics, semi-synthetic penicillin

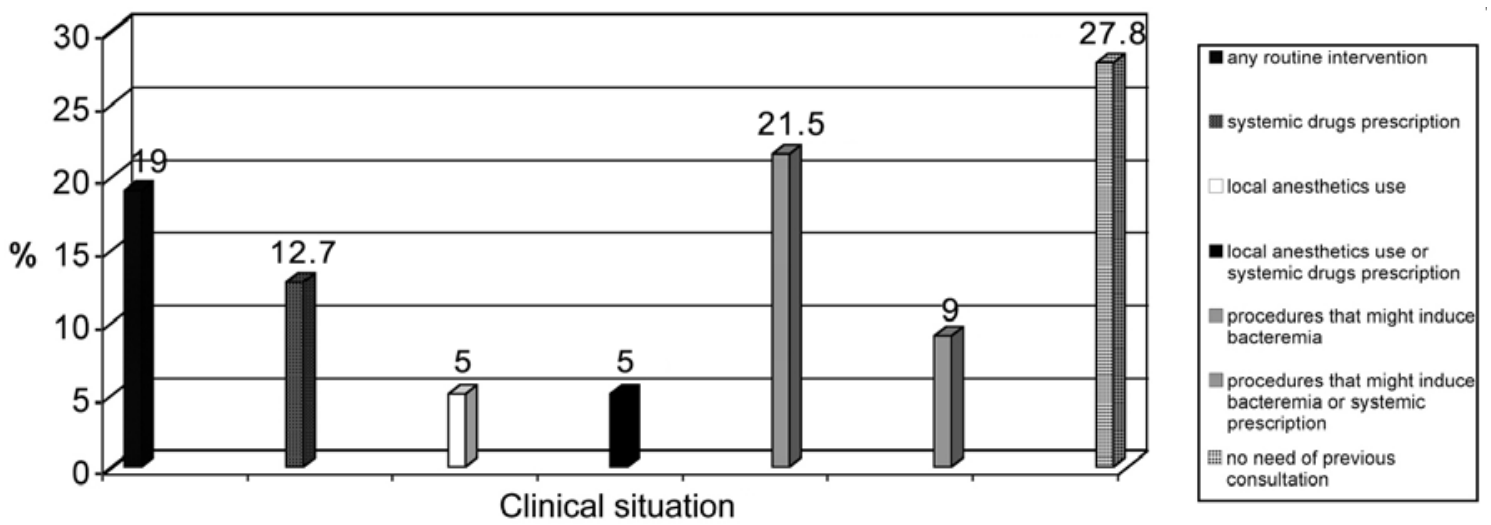

FIGURE 1- Clinical situations in which obstetricians $(n=79)$ would like to be previously consulted 
(amoxicillin and ampicillin) and cephalosporin were selected as first-choice drugs by nearly all professionals (95\%). In case of allergy to penicillin, the drug of choice was cephalosporin according to 28 obstetricians $(35.4 \%)$ and macrolides (erythromycin) according to 31 doctors (39.2\%).

As to the indication of analgesics, acetaminophen was the first choice of $100 \%$ of interviewees. Some professionals also considered the use of dipyrone (19\%), acetylsalicylic acid $(6 \%)$ and codeine $(2.5 \%)$.

The recommendations as to the use of anti-inflammatory drugs are presented in Figure 2.

Concerning the use of local anesthetics, 54 obstetricians recommended lidocaine $(68.3 \%), 41$ (52\%) recommended use of lidocaine without vasoconstrictor and 13 (16.5\%) professionals indicated lidocaine with vasoconstrictor. There was statistically significant difference between time since graduation and indication of vasoconstrictors ( $t$ test; $\mathrm{p}=0.011$ ), this practice was more frequent among physicians with shorter time of professional exercise. Twenty-two obstetricians indicated other anesthetic salts and 3 professionals considered such a recommendation should be made by the dentist.

Twenty-seven professionals (34.2\%) were unaware of the possible correlation between periodontal disease and risk of premature labor.

The rate of prenatal fluoride administration is expressed in Figure 5.

There were no statistically significant differences $(p<0.05)$ between recommendations of professionals from the cities of Bauru and Londrina as to prescription of fluoride, drugs and recommendation of local anesthetics.

\section{Dentists}

The period of professional practice of dentists ranged from 9 to 34 years (mean 19 years). The 37 professionals worked in public health centers, 17 also worked in private practice and 3 worked in both activities and were also professors.

Thirty-one dentists $(83.8 \%)$ reported that they had received specific information on dental care to pregnancy women. Twenty-seven (73\%) felt safe to perform dental care in these patients, while $15(40.5 \%)$ of the professionals feel the need to consult the patient's obstetrician before any routine procedure (Figure 3 ).

Thirty dentists $(81 \%)$ considered that emergency care (control of acute infection, pain relief) should be performed throughout pregnancy. One professional contraindicated dental care during pregnancy.

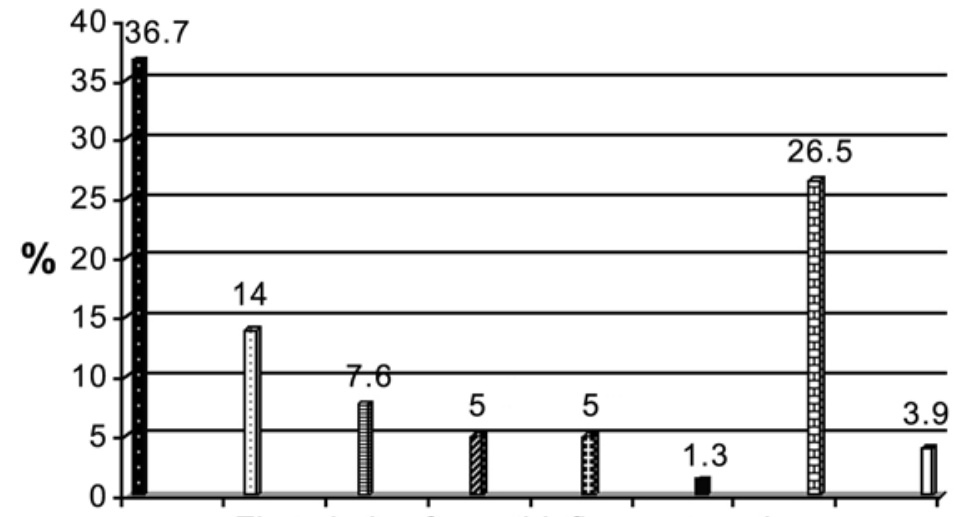

First choice for anti-inflammatory drugs

\begin{tabular}{|l|}
$\square$ diclofenac \\
acetaminophen \\
$\square$ nimesulide \\
acorticosteroids \\
piroxicam \\
contraindicate \\
anti-inflammatory drugs \\
no response
\end{tabular}

FIGURE 2- Recommendations of obstetricians as to the use of first-choice anti-inflammatory drugs during pregnancy ( $\mathrm{n}=79$ )

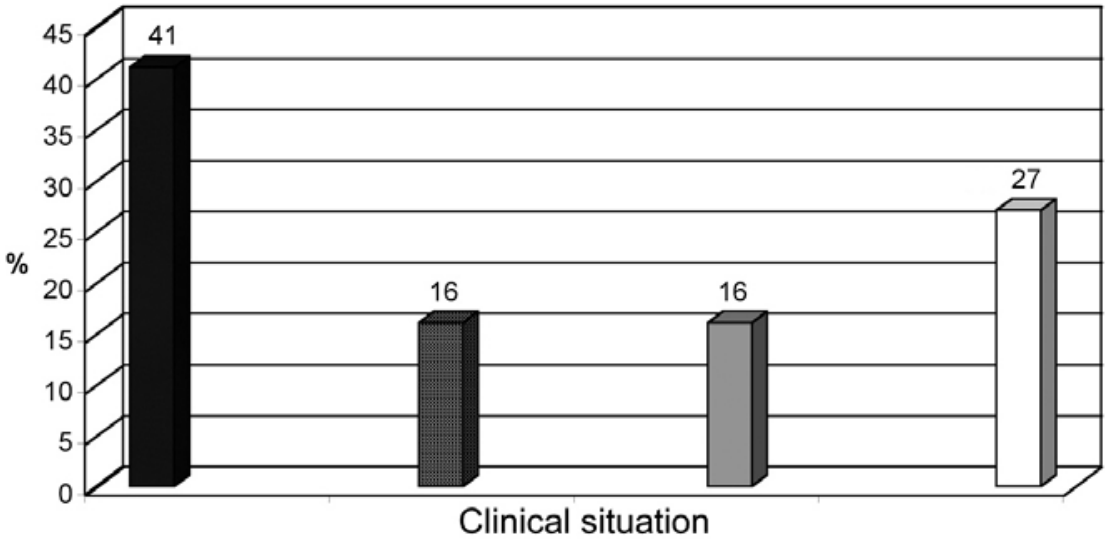

any routine intervention

systemic drugs prescription

procedures that might induce bacteremia

high risk pregnancy

FIGURE 3- Clinical situations in which dentists $(n=37)$ would like to previously consult the obstetrician 


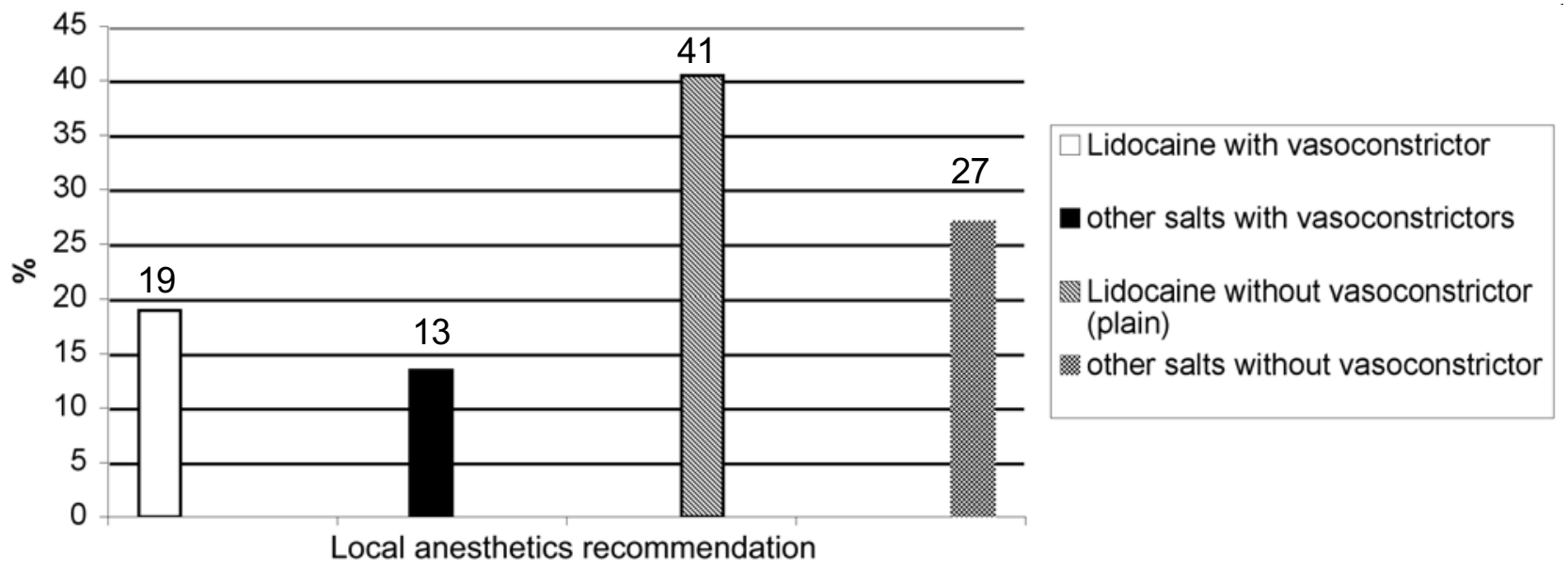

FIGURE 4- Recommendation of local anesthetics by dentists

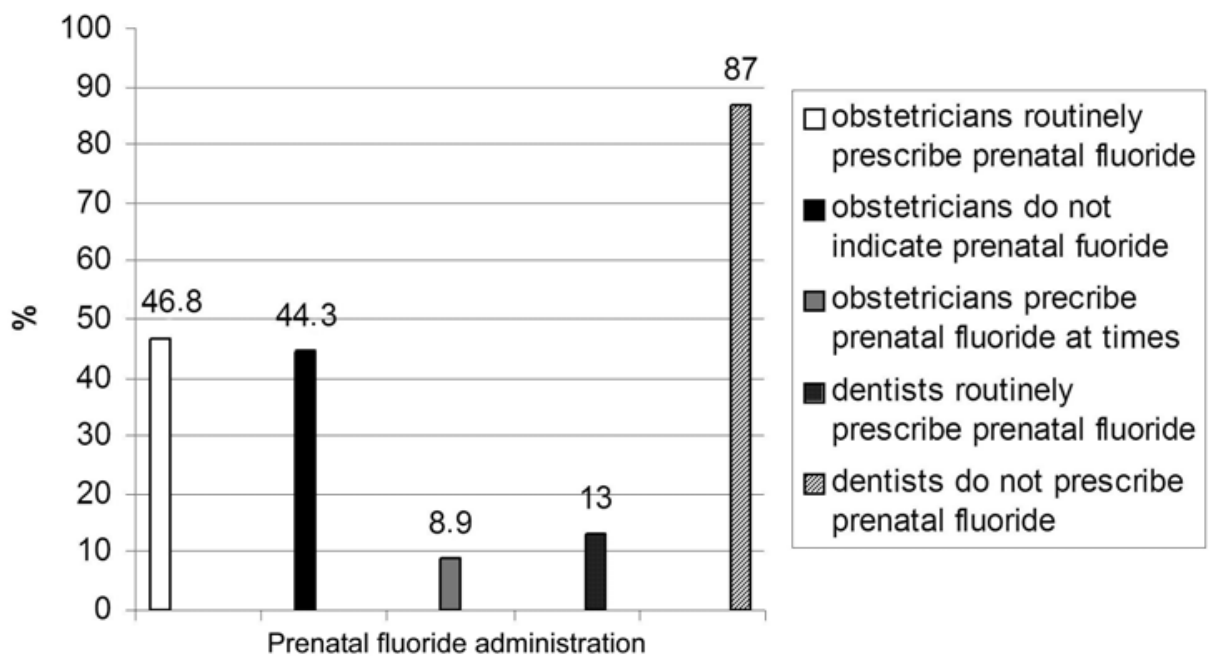

FIGURE 5- Prenatal fluoride administration practice among professionals

Taking of dental radiographs was considered safe throughout pregnancy by 6 dentists $(16.2 \%)$. Fourteen professionals $(37.8 \%)$ indicated radiography only after the first trimester and 14 professionals $(37.8 \%)$ contraindicated this procedure during pregnancy. Three professionals preferred to consult the patient's obstetrician as to the indication.

Regarding the prescription of antibiotics, semi-synthetic penicillin and cephalosporin were the first choice of 29 professionals $(78.3 \%)$. Six professionals only prescribed after consultation with the patient's obstetrician. In case of allergy to penicillin, 21 professionals $(56.7 \%)$ considered that previous consultation with the patient's obstetrician was necessary.

Acetaminophen was the first choice of analgesics for 25 professionals $(67.6 \%)$, dipyrone for $8(21.6 \%)$ and acetylsalicylic acid for 1 . Three professionals considered previous consultation with the patient's obstetrician as necessary.

Acetaminophen was the first choice as anti-inflammatory drug for 11 dentists $(29.7 \%)$, as well as diclofenac (29.7\%). Eleven professionals $(29.7 \%)$ considered that previous consultation with the patient's obstetrician is necessary.

Anesthetic recommendations are described in Figure 4, and prenatal fluoride administration in Figure 5.

Sixteen dentists (43.2\%) were unaware of the relationship between periodontal disease and risk of premature labor, and 14 professionals $(37.8 \%$ ) did not know about granuloma gravidarum.

\section{DISCUSSION}

In Londrina, the rate of returned answered represented almost $60 \%$ of professionals contacted by mail. This is a representative number, although one could consider that professionals interested in participating in this type of study, which evaluates their own professional knowledge, could be more receptive or distinguished from the others. In Bauru, the questionnaires were responded by obstetricians working in the municipal public health service, adding up to 21 physicians, which represent nearly $30 \%$ of professionals in the city. However, in study data analysis, the workplace disclosed statistically significant differences. Considering 
the bias, the results of the present study cannot be extrapolated, but they indicate that some aspects related to dental care during pregnancy should be further diffused to allow the establishment of proper treatment protocols.

Recent studies suggest a positive correlation between presence and severity of periodontal disease and risk of premature labor and low birth-weight babies ${ }^{9,11,19,25}$. It has been demonstrated that the induction of high levels of prostaglandins by periodontal infection would disrupt the hormonal homeostasis ${ }^{19,25}$. However, in the present study, even though 52 obstetricians $(65.8 \%)$ reported that they were aware of this subject, only $29(36.7 \%)$ routinely refer the pregnant patients to dental care. This and previous studies demonstrate that dental care is only indicated in the presence of patient complaint ${ }^{16}$.

Gaffield, et al. ${ }^{4}$ conducted a large survey in the United States and observed that less than $35 \%$ of pregnant women had received dental care during their last pregnancy, and only half of patients reporting some oral problem looked for care. In Brazil, despite the lack of national surveys, regional studies demonstrate that untreated dental problems are evident in pregnant women with low educational level and low income ${ }^{20,29}$. In addition to difficulties such as the high cost and difficult access to treatment, cultural beliefs that dental care would pose risk to the baby impair the search for care.

Conversely, there is fear or lack of training of dentists as to the care of pregnant women, ${ }^{5,8,26}$ even though $73 \%$ of dentists answered to a direct question as "feeling safe to perform dental care in pregnant patients". Nearly $40 \%$ of dentists interviewed in this study would like to consult the patient's obstetrician before any intervention, and many affirmed to feel unable to prescribe systemic drugs.

Shrout, et al..$^{22}$, in a study on 80 North American obstetric centers, observed that $79 \%$ of obstetricians considered consultation as necessary before performing clinical procedures that could induce bacteremia, and only $9 \%$ indicated consultation before routine treatment. However, even dental prophylaxis may induce bacteremia and physicians may be unaware of this aspect.

The interaction between obstetricians and dentists should be encouraged to allow a more thorough work. However, the dentist should be trained to provide independent care. The obstetrician provides additional information on the health status of the patient, yet the dentist is legally responsible for any therapeutic interventions or omissions ${ }^{1}$.

Dental intervention should be concentrated in the second trimester of pregnancy, whenever possible. Minimally invasive restorative procedures, such as the atraumatic restorative treatment (ART), are well indicated ${ }^{30}$. Emergency care should be performed regardless of the gestational period.

Radiographs to complement clinical examination are indicated in the presence of symptoms or suspected disease, as well as to allow adequate treatment $t^{5,8,23}$. This disagrees with the responses of $84 \%$ of dentists, who would not take radiographs during the first trimester, even when indicated.
Not taking radiographs when there is indication might lead to poor diagnosis and undertreatment, bringing about other risks to the pregnant woman and baby.

With regard to prescription of antibiotic drugs, most professionals responded in accordance with the scientific literature, considering the international recommendation of FDA (Food and Drug Administration). Penicillin, cephalosporin, clindamycin, erythromycin stearate and azithromycin are categorized as B and may be prescribed during pregnancy. Use of erythromycin estolate should be restricted due to hepatotoxicity ${ }^{1,6,18}$. Aminoglycosides are contraindicated due to their ototoxicity, as well as tetracycline, which causes tooth discoloration (category D). Nearly $15 \%$ of patients with allergy to penicillin may present cross-reaction to cephalosporin. This aspect should be considered during selection of alternative antibiotics.

Acetaminophen is categorized as B at therapeutic doses. It is not associated with complications during pregnancy and is the first choice of analgesic drug.

Administration of anti-inflammatory drugs, including aspirin, is less favorable. These drugs are categorized as D on the third trimester because they are associated with uterine inertia, labor complications, hemorrhage and constriction of the fetal arterial duct ${ }^{6,18}$. Interpretation of the prescription of anti-inflammatory drugs is limited, since the gestational trimester, dose and treatment duration may modify their classification and indication.

The use of local anesthetics with vasoconstrictors is considered as safe throughout pregnancy ${ }^{1,7,8,18,24,26}$. However, the anesthetic salt and type and concentration of vasoconstrictor should be observed. The vasoconstrictor felypressin should be avoided due to the potential risk of uterine contraction, as well as bupivacaine salt, due to its long period of action ${ }^{1}$. Methemoglobinemia is a potential side effect of the administration of large doses of prilocaine and articaine ${ }^{15}$. Mepivacaine is not well metabolized by the liver of the fetus. According to most authors, the first choice of anesthetic drug should be lidocaine hydrochloride associated with vasoconstrictor adrenaline at the concentration of $1: 100,000^{1,7,8,18,24,26}$. However, in this study, only $19 \%$ of the dentists and $16.5 \%$ of the obstetricians made this recommendation.

Local anesthetics are vasodilator drugs. The use of vasoconstrictors is beneficial because they significantly reduce the rate of systemic absorption and consequently the toxicity of the anesthetic drug (lower serum concentration $)^{15,27}$. Its presence also increases the depth and duration of anesthetic action, demanding smaller amount of the anesthetic drug.

Despite the indications of recent literature, this study revealed a noticeable fear as to the prescription of anesthetics with vasoconstrictors of both medical and dental doctors. This restriction is probably related to the potential risk of these substances to impair the uterine blood flow and stimulate the cardiac function. However, the quantity of adrenaline or epinephrine applied for dental care is so low that this risk is improbable when adequate substances and techniques are used, i.e. with previous 
aspiration to avoid accidental intravascular injection and following the maximum dose of two anesthetic tubes per clinical session ${ }^{1,7,8,15,18,24,27}$.

By itself, pregnancy is not a contraindication for use of local anesthetics with vasoconstrictors. However, their use should be avoided in special situations, such as untreated hypertension and diabetes, severe heart disease, hyperthyroid state or patients taking drugs that may promote adverse interactions, such as tricyclic antidepressants, nonselective $\beta$ blockers and cocaine, or patients with allergy to sulfites ${ }^{1,15,27}$

Systemic prenatal fluoride was routinely recommended by nearly $47 \%$ of dentists interviewed in this study, as also reported by Losso and Ramalho ${ }^{14}$ in the metropolitan region of Curitiba, and close to the findings of Menoli and Frossard $^{16}(52 \%)$. The main issue considered to contraindicate prescription was fluoridation of the public water supply, as reported elsewhere ${ }^{14}$. However, prescription is not indicated due to the lack of scientific evidences that prenatal fluoride supplementation might bring any additional benefits to the teeth of the fetus ${ }^{13}$, especially as most commonly recommended by obstetricians, i.e. associated with polyvitamins, in which the presence of calcium and other minerals nearly inactivates its action ${ }^{3}$.

Therefore, in the group of interviewed professionals, divergence was observed from the scientific literature as to the recommendations on dental radiographs, local anesthetics and prenatal fluoride supplementation. Also, most dentists were insecure to prescribe systemic drugs and referred the patients to obstetricians before any routine intervention, which might impair the patient flow, mainly in public services.

\section{CONCLUSION}

Although the results of the present study cannot be extrapolated, they clearly demonstrate that dental management during pregnancy still presents some deviations from scientific literature recommendations, indicating the need to update health care professionals involved in prenatal assistance in order to establish more accurate guidelines.

\section{REFERENCES}

1- Andrade ED. Terapêutica medicamentosa em odontologia. São Paulo: Artes Médicas; 2002

2- Barak S, Oettinger-Barak O, Oetinger M, Machtei EE, Peled M, Ohel G. Common oral manifestations during pregnancy: a review. Obstet Gynecol Surv. 2003;58(9):624-8.

3- Fernandes LMAG, Cury JA. Avaliação metabólica do flúor prénatal. Rev Bras Med. 1993;50:1546-54.

4- Gaffield ML, Gilbert BJ, Malvitz DM, Romaguera R. Oral health during pregnancy - An analysis of information collected by the pregnancy risk assessment monitoring system. J Am Dent Assoc. 2001;132(7):1009-16.
5- Gajendra S, Kumar JV. Oral health and pregnancy: a review. N Y State Dent J. 2004;70(1):40-4.

6- Haas DA, Pynn BR, Sands TD. Drug use for the pregnant and lactating patient. Gen Dent. 2000;48(1):54-60.

7- Haas DA. An update on local anesthetics in dentistry. J Can Dent Assoc. 2002;68(9):546-51.

8- Hilgers KK, Douglass J, Mathieu GP. Adolescent pregnancy: A review of dental treatment guidelines. Pediatr Dent. 2003;25(5):45967.

9- Jeffcoat MK, Geurs NC, Reddy MS, Cliver SP, Goldenberg RL, Hauth JC. Periodontal infection and preterm birth - results of a prospective study. J Am Dent Assoc. 2001;132(7):875-80.

10- Jeffcoat MK, Haulth JC, Geurs NC, Reddy MS, Cliver SP, Hodgkins $\mathrm{PM}$, et al. Periodontal disease and preterm birth: results of a pilot intervention study. J Periodontol. 2003;74(8):1214-8.

11- Khader YS, Ta'ani Q. Periodontal disease and the risk of pretermbirth and low birth weight: a meta-analysis. J Periodontol. 2005;76(2):161-5.

12- Kohler B, Andreen I, Jonsson B. The effect of caries-preventive measures in mothers on dental caries and the oral presence of the bacteria Streptococcus mutans and Lactobacilli in their children. Arch Oral Biol. 1984;29(11):879-83.

13- Leverett DH, Adair SM, Vaughan BW, Proskin HM, Moss ME. Randomized clinical trial of the effect of prenatal fluoride supplements in preventing dental caries. Caries Res. 1997;31(3):174-9.

14- Losso EM, Ramalho GM. Avaliação de prescrição de suplementos de flúor pré-natal em Curitiba e região metropolitana. Rev Bras Ginecol Obstet. 2001;23:391-6.

15- Malamed SF. Handbook of local anesthesia. St. Louis : Ed. Mosby; 1997.

16- Menoli APV, Frossard WTG. Perfil de médicos ginecologistas/ obstetras de Londrina com relação à saúde oral da gestante. Semina. 1997; 18:34-42.

17- Mills LW, Moses DT. Oral Health during pregnancy. MCN Am J Matern Child Nurs. 2002;27(5):275-81.

18- Moore PA. Selecting drugs for the pregnant dental patient. J Am Dent Assoc. 1998;129(9):1281-6.

19- Offenbacher S, Jared HL, O’Reilly PG, Wels SR, Salvi GE, Lawrence $\mathrm{HP}$, et al. Potential pathogenic mechanisms of periodontitis associated pregnancy complications. Ann Periodontol. 1998;3(1):233-50.

20- Oliveira BH, Nadanovsky P. The impact of oral pain on quality of life during pregnancy in low-income Brazilian women. J Orofac Pain. 2006;20(4):297-305.

21- Salvolini E, Giorgio R, Curatola A, Mazzanti L, Fratto G. Biochemical modifications of human whole saliva induced by pregnancy. Br J Obstet Gynaecol. 1998;105(6):656-60.

22- Shrout MK, Comer RW, Powell BJ, McCoy BP. Treating the pregnant dental patient: four basic rules addressed. J Am Dent Assoc. $1992 ; 123(5): 75-80$

23- Suresh L, Radfar L. Medical management update - Pregnancy and lactation. Oral Surg Oral Med Oral Pathol Oral Radiol Endod. 2004;97(6):672-82. 
24- Tortamano N, Armonia PL. Anestésicos locais. In: Tortamano N, Armonia PL. Guia terapêutico odontológico. São Paulo: Ed. Santos; 2003. p.30-41.

25- Tucker R. Periodontitis and pregnancy. J R Soc Health. 2006;126(1):24-7.

26- Turner MD, Singh F, Glickman RS. Dental management of the gravid patient. N Y State Dent J. 2006;72(6):22-7.

27- Yagiela JA. Adverse drug interactions in dental practice: interactions associated with vasoconstrictors. Part V of a series. J Am Dent Assoc. 1999;130(5):701-9.

28- Yalcin F, Eskinazi E, Soydinc M, Basegmez C, Isik G, Berber L, et al. The effect of sociocultural status on periodontal condition in pregnancy. J Periodontol. 2002;73(2):178-82.

29- Zanata RL, Navarro MFL, Pereira JC, Franco EB, Lauris JRP, Barbosa SH. Effect of caries preventive measures directed to expectant mothers on caries experience in their children. Braz Dent J. $2003 ; 14(2): 75-81$.

30- Zanata RL, Navarro MFL, Barbosa SH, Lauris JRP, Franco EB Clinical evaluation of three restorative materials applied in a minimal intervention caries treatment approach. J Public Health Dent. $2003 ; 63(4): 221-6$. 